\title{
Characterization of an engineered cellulose based membrane by thiol dendrimer for heavy metals removal
}

\author{
Manuel Algarra a,*, María Isabel Vázquez ${ }^{\mathrm{b}}$, Beatriz Alonso $^{\mathrm{c}}$, Carmen María Casado $^{\mathrm{c}}$, \\ Juan Casado ${ }^{\mathrm{d}}$, Juana Benavente ${ }^{\mathrm{b}, *}$ \\ ${ }^{a}$ Dept. Inorganic Chemisty, Faculty of Science, University of Málaga, 29071 Málaga, Spain

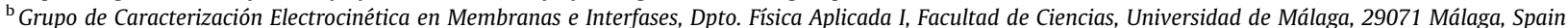 \\ ${ }^{\mathrm{C}}$ Dpto. Química Inorgánica, Universidad Autónoma de Madrid, Cantoblanco, 28049 Madrid, Spain \\ ${ }^{\mathrm{d}}$ Dpto. Química Física, Facultad de Ciencias, Universidad de Málaga, 29071 Málaga, Spain
}

\section{H I G H L I G H T S}

- Thiol polypropylenimine

(DAB-3-(SH) 16 ) dendrimer engineered cellulosic support membranes.

- Chemical, elastic and electrical characterizations of original and engineered membranes.

- Diffusive permeability reduction of heavy metal $\left(\mathrm{Cd}^{2+}, \mathrm{Hg}^{2+}\right.$ and $\left.\mathrm{Pb}^{2+}\right)$ solutions.

- Potential application in electrochemical devices for heavy metal water remediation.

\section{A R T I C L E I N F O}

\section{Article history:}

Received 7 November 2013

Received in revised form 13 May 2014

Accepted 19 May 2014

Available online 27 May 2014

\section{Keywords:}

Thiolated DAB dendrimer

Engineered cellulosic membrane

Diffusive permeability reduction

Heavy metals remediation

\section{G R A P H I C A L A B S T R A C T}

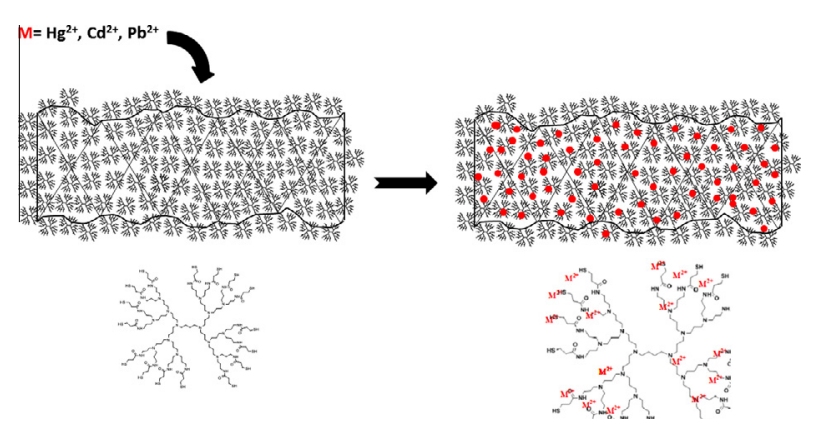

\begin{abstract}
A B S T R A C T
Diaminobutane based poly(propyleneimine) dendrimer functionalized with sixteen thiol groups, DAB-3-(SH) ${ }_{16}$, was successfully embeded in a swollen cellulosic support in order to achieve an easily handle engineered membrane. The membrane was characterised by physicochemical, electrical and transport measurements, and the effect of the dendrimer was established by comparing these results with those obtained for the original cellulosic support. Results show that dendrimer inclusion improves the membrane elastic behaviour (Young modulus increase around 20\%), while a significant reduction in the permeation of toxics heavy metals $\left(\mathrm{Cd}^{2+}, \mathrm{Hg}^{2+}\right.$ and $\left.\mathrm{Pb}^{2+}\right)$ was also obtained, which avails the possible application of dendrimer-modified membrane in electrochemical devices for water remediation.
\end{abstract}

(c) 2014 Elsevier B.V. All rights reserved.

\section{Introduction}

Membrane processes such as ultrafiltration, nanofiltration and reverse osmosis are nowadays currently applied to sea and brackish water desalting [1,2], while liquid supported membranes and polymer inclusion membranes have been proposed for treatment of industrial wastewater and metal cations recovery $[3,4]$. In fact,

\footnotetext{
* Corresponding authors. Tel.: +34 952131929; fax: +34 952132000.

E-mail addresses: malgarra67@gmail.com (M. Algarra), j_benavente@uma.es (J. Benavente).
}

heavy metal contamination of natural and wastewaters has become an important environmental problem, being cadmium, nickel, lead, mercury, copper and zinc the most hazardous [5,6]. Among the strategies proposal for metal ions removal from water diffusive separation by heavy metal contaminated water passes through a membrane is a simple technique applicable to electrochemical devices.

Regenerated cellulose (RC) is a natural material used in membrane manufacture due to their high hydrophilicity and rather good chemical and solvent resistance. Particularly, RC membranes exhibit very high swelling degrees when they are in contact with 
aqueous solutions $[7,8]$, which can favor the inclusion of different substances in cellulose cross-linked structure and confer them particular characteristics able to affect the mass transport across the membranes $[9,10]$.

Dendrimers and their derivatives are substances with diverse analytical, biomedical and environmental applications [11-15] due to their unique molecular structure, easy functionalization and manipulation of their terminal groups [16-21]. Dendritic polymers basically consist of a multi-functional core, high degree of repeated branching units and high density of surface functional groups [22]. A commercial poly(amidoamine) dendrimer (PAMAM) has been used in separation systems for recovery heavy metals from aqueous solution by means of chelating agents in pollution remediation processes. Particularly, aqueous heavy metal solutions treated with PAMAM previous to pass them through a membrane (ultrafiltration technique) has been proposed for water and soil remediation [23-27]. Other researchers have obtained functionalized membranes with PAMAM, hydroxyl PAMAM and carboxyl PAMAM for $\mathrm{CO}_{2} / \mathrm{N}_{2}$ separation and as models for adsorption of dye molecules [28-31]. Recently, raw PAMAM, aromatic PAMAM and PAMAM coated with polyethylene glycol have been used in the modification of polymeric reverse osmosis membranes for $\mathrm{Ba}^{2+}, \mathrm{Na}^{+}$and $\mathrm{As}^{3+}$ recovery [32-34] and other contributions on dendrimers immobilization have also been proposed [35-37]. In this context, in a previous work we analyzed the possible use of a fifth generation thiol poly(propyleneimine) dendrimer coated with CdSe and embedded in a hydrophilic cellulosic membrane as cadmium sensor in liquid media [10], where the fluorescence character of the modified dendrimer allows us to confirm its presence in the structure of the cellulosic support.

In this work, a diaminobutane based poly(propyleneimine) dendrimer functionalized with sixteen thiol groups, DAB-3-( $\mathrm{SH})_{16}$, was included in a regenerated cellulose support in order to obtain a nano-engineered modified membrane. Original and modified membranes were characterised by physicochemical and diffusion measurements to see the effect of the dendrimer by comparing the results obtained with both membranes. Particularly, elastic and chemical information was obtained from tensile-strength/ elongation curves and Raman spectroscopy, while changes in electrical resistance were associated to differences electrolytes uptake; moreover reduction in toxic heavy metals $\left(\mathrm{Cd}^{2+}, \mathrm{Hg}^{2+}\right.$ and $\left.\mathrm{Pb}^{2+}\right)$ pemeabilities were determined from diffusion measurements. Difference in this parameter supports the possible application of this engineered membrane in electrochemical device for water remediation.

\section{Materials and methods}

\subsection{Dendrimer}

The thiolated dendrimer DAB-3-(SH) 16 was synthesized by treatment of the third diaminobutane based poly(propyleneimine) dendrimer DAB-3-( $\left.\mathrm{NH}_{2}\right)_{16}$ with an excess of 3-mercaptopropanyl$\mathrm{N}$-hydroxysuccinimide ester in dichloromethane solution at room temperature, according to the procedure already published [38]. Fig. 1 presents a scheme of the studied dendrimer with the sites for cation anchorage.

\subsection{DAB-3-(SH) ${ }_{16}$ dendrimer inclusion in the support membrane}

A flat regenerated cellulose (RC) swollen membrane from Cellophane Española, S.A. (Burgos, Spain) with a content of $0.04 \mathrm{~kg} \mathrm{~m}^{-2}$ of regenerated cellulose (sample $\mathrm{RC} / 4$ ) was used as support. The swelling degree of this membrane, $S_{\mathrm{w}}=\left(\Delta x_{\mathrm{w}}-\Delta x_{\mathrm{d}}\right) / \Delta x_{\mathrm{d}}$, where $\Delta x_{\mathrm{d}}$ and $\Delta x_{\mathrm{w}}$ represent the thickness of dry and wet samples, is $S_{w}=(79 \pm 4) \%$. Pieces of the RC- 4 membrane were immersed in a water solution of the dendrimer for $2 \mathrm{~h}$ and dried at room temperature (sample $\mathrm{RC} / 4+$ dendrimer). Fig. 2 shows a scheme of the easy to hand nano-engineered $\mathrm{RC} / 4+$ dendrimer flat membrane.

\subsection{Raman measurements}

$1064 \mathrm{~nm}$ FT-Raman spectra were obtained in an FT-Raman accessory kit (FRA/106-S) of a Brucker Equinox 55 FT-IR interferometer. A continuous-wave Nd-YAG laser working at $1064 \mathrm{~nm}$ was employed for excitation. A germanium detector operating at liquid nitrogen temperature was used. Raman scattering radiation was collected in a back-scattering configuration with a standard

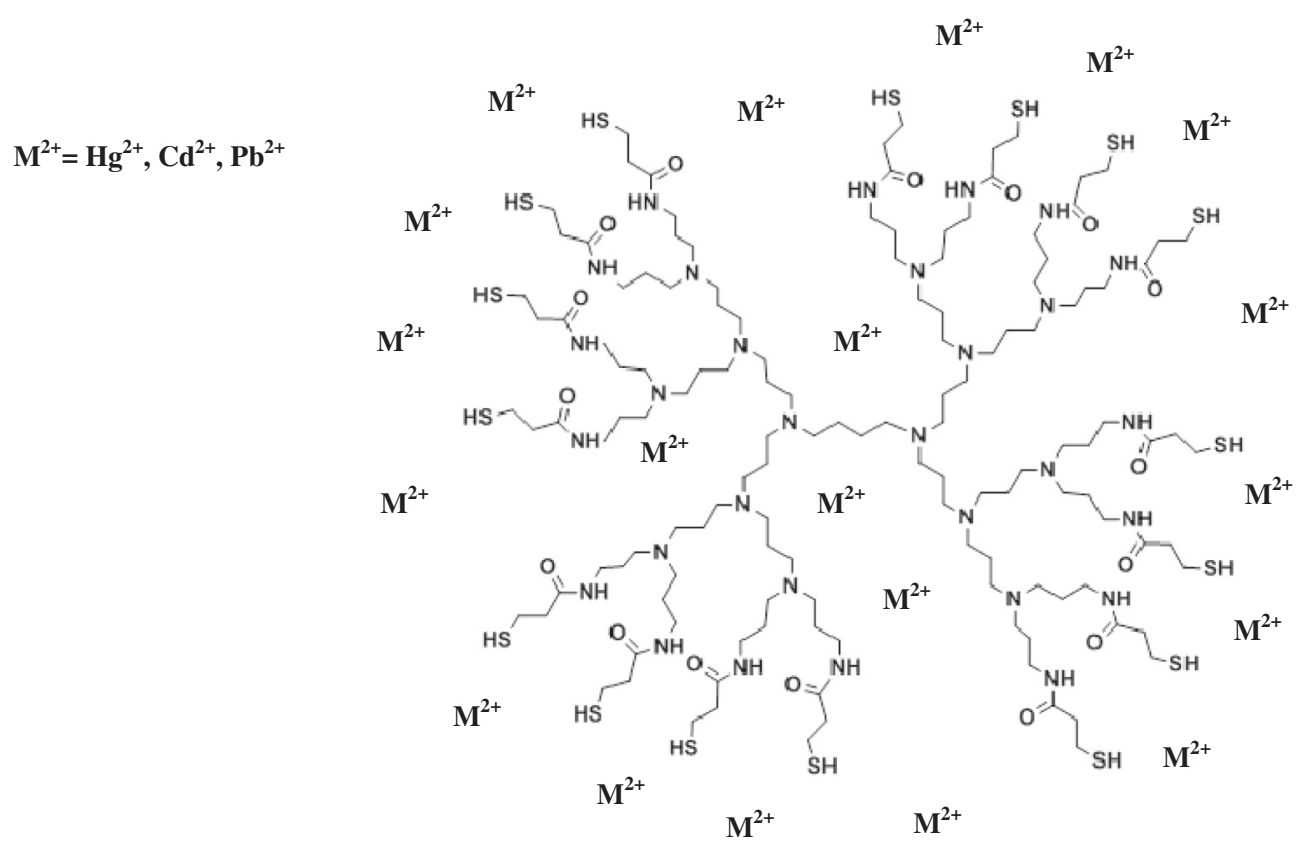

Fig. 1. Molecular representation of the interaction of DAB-3-(SH) ${ }_{16}$ dendrimer with $\mathbf{M}^{2+}$. 


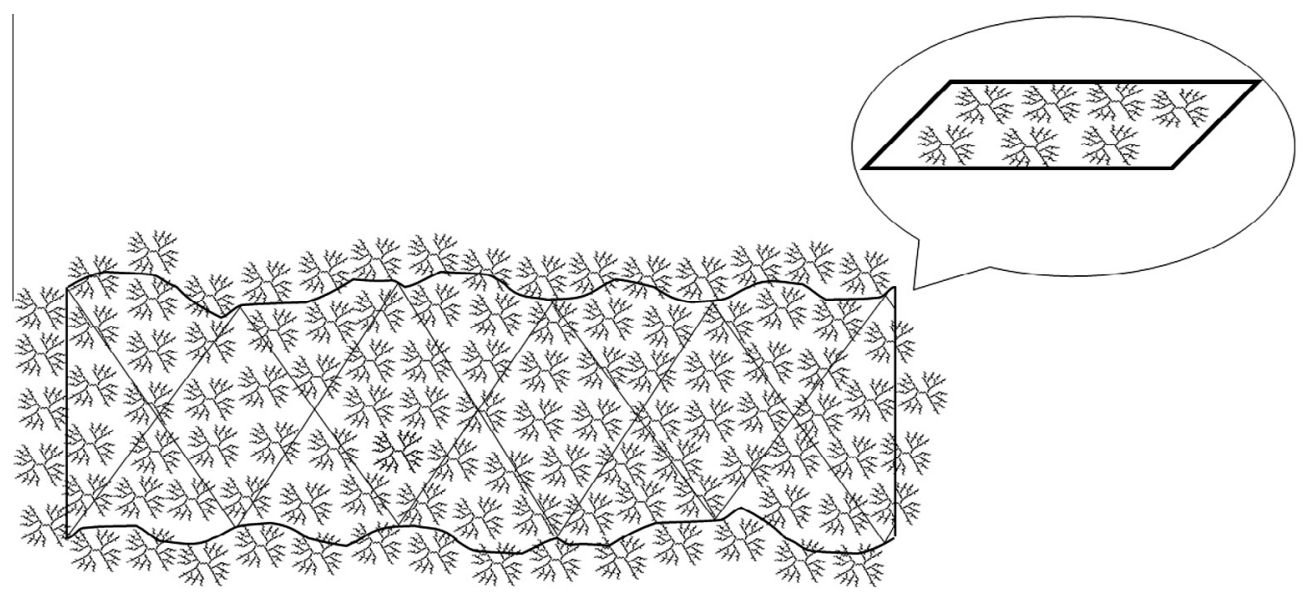

Fig. 2. Schematic representation of the coated $\mathrm{RC} / 4$ membrane by $\mathrm{DAB}-3-(\mathrm{SH})_{16}$ dendrimer.

spectral resolution of $4 \mathrm{~cm}^{-1} .2000$ scans were averaged for each spectrum.

\subsection{Elastic measurements}

Measurements for the elastic characterization of membranes were performed with a force digital gauge (Mark-T, ES20 model) connected to a computer, with a maximum tension of $100 \mathrm{~N}$, length accurate of $\pm 0.01 \mathrm{~mm}$ and a strength rate of $10 \mathrm{~mm} / \mathrm{s}$. Samples of the same size $(1 \mathrm{~cm}$ width $\times 4 \mathrm{~cm}$ length) of both membranes were used and measurements carried out with the membranes placed in a water tank.

\subsection{Impedance spectroscopy measurements}

The test cell for impedance spectroscopy (IS) measurements consisted of a Teflon support on which two Pt electrodes were placed and screwed down. The electrodes were connected to an Frequency Response Analyzer (Solartron 1260, England) and measurements were recorded for 100 data points with frequency ranging between $1 \mathrm{~Hz}$ and $10^{7} \mathrm{~Hz}$, at a maximum voltage of $0.01 \mathrm{~V}$. Impedance measurements were performed with dry and wet samples of both RC/4 and RC/4+dendrimer membranes; wet samples mean immersed for $24 \mathrm{~h}$ in a $1 \mathrm{mM}$ solution of the different electrolytes $\left(\mathrm{CdCl}_{2}, \mathrm{PbCl}_{2}\right.$ and $\left.\mathrm{HgCl}_{2}\right)$, which allows us to determine differences associated to the uptake of the different cations in the membrane electrical parameters as well as the dendrimer effect.

The impedance is a complex number, $Z=Z_{\text {real }}+\mathrm{j} Z_{\text {img, }}$, which can be separated into real and imaginary parts by algebra rules. Membrane electrical parameters can be determined by analyzing the impedance plot $\left(Z_{\text {real }}\right.$ versus $-Z_{\text {img }}$ ) by considering an equivalent circuit formed by a parallel association of a resistance $(R)$ and a capacitor $(C)$, which is related to $Z_{\text {real }}$ and $Z_{\text {img }}$ by the following expressions [39]:

$Z_{\text {real }}=\left(R /\left[1+(\omega R C)^{2}\right]\right), Z_{\text {img }}=-\left(\omega R^{2} C /\left[1+(\omega R C)^{2}\right]\right)$

where $\omega$ represents the angular frequency $(\omega=2 \pi \mathrm{f})$. Complex systems usually present a distribution of relaxation times and the resulting plot is a depressed semi-circle, which is associated to a non-ideal capacitor or constant phase element (CPE) [39].

\subsection{Salt diffusion measurements}

Diffusion measurements allow the determination of the diffusive permeability $\left(P_{\mathrm{s}}\right)$ and they were performed in a dead-end test cell similar to that previously described [40]. The membranes were placed in the middle of two symmetric half-cells separating two different solutions, one donor $\left(c_{\mathrm{d}}=0.001 \mathrm{M}\right.$ of $\mathrm{CdCl}_{2}, \mathrm{PbCl}_{2}$ and $\mathrm{HgCl}_{2}$, respectively) and distilled water as receiving solution (initially, $\left.c_{\mathrm{r}}=c_{\mathrm{r}}^{\mathrm{o}}=0\right)$, and concentration-polarization at the membrane/solution interfaces was minimized by using two Tefloncovered magnetic stirrers at a stirring rate of $540 \mathrm{rpm}$. Variation in the conductivities of the solutions in feed and receiving half-cells were recorded versus time by means of two conductivity cells, each one placed in one half-cell, and connected to two digital conductivity-meters (Crison GLP 31). Conductivity-concentration calibration curves for each electrolyte were used for receiving concentration determination. Measurements were carried out at room temperature $(25 \pm 2)^{\circ} \mathrm{C}$ and standard $\mathrm{pH}(5.8 \pm 0.3)$.

\section{Results and discussion}

Possible chemical changes in the cellulosic support membrane as a result of both dendrimer inclusion and heavy metal uptakes after membrane immersion for $24 \mathrm{~h}$ in water or $1 \mathrm{mM}$ of the studied electrolytes $\left(\mathrm{CdCl}_{2}, \mathrm{PbCl}_{2}\right.$ and $\left.\mathrm{HgCl}_{2}\right)$ were analyzed by Raman spectroscopy. Fig. 3 displays the Raman spectra of three samples, which correspond to: $\mathrm{RC} / 4$ (a) and $\mathrm{RC} / 4+$ dendrimer (b) dry membranes, while Fig. 3(c) shows the spectra of this latter sample after immersion in the $\mathrm{HgCl}_{2}$ aqueous solution (wet membrane sample). As can be observed, the spectrum of the $\mathrm{RC} / 4+$ dendrimer does not

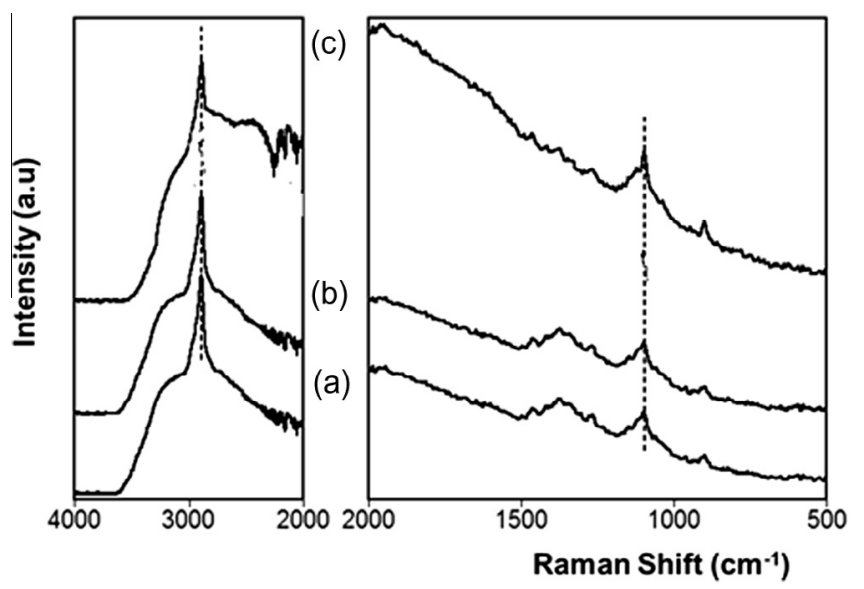

Fig. 3. $1064 \mathrm{~nm}$ FT-Raman spectra of: (a) RC/4 dry membrane, (b) RC/4+dendrimer dry membrane, (c) $\mathrm{RC} / 4+$ dendrimer membrane embedded of a $10^{-3} \mathrm{M} \mathrm{HgCl}_{2}$ aqueous solution. 
undergoes any appreciable transformation when compared with the original RC/4 support; however, as a result of its immersion in a water solution of $\mathrm{HgCl}_{2}$, some changes in the spectral background are observed which are specially notable in the region around $1400 \mathrm{~cm}^{-1}$, but they do not reveal chemical transformation in the-RC/4+dendrimer membrane but electrolyte absorption driven by physical forces.

Moreover, very similar Raman spectra for the $\mathrm{RC} / 4+$ dendrimer membrane embedded of $\mathrm{HgCl}_{2}$ and $\mathrm{CdCl}_{2}$ aqueous solutions can also be observed in Fig. 4, indicating that no changes in the membrane chemical structure have taken place, but some differences exist in the spectrum of the RC/4+dendrimer membrane with $\mathrm{PbCl}_{2}$, although no new bands assignable to the formation of new chemical structures are detected. The change in spectral background in the $\mathrm{PbCl}_{2}$ case might be again an indication of the involvement of distinctive physical phenomena (reversible from a chemical point of view).

To estimate physical changes in the cellulosic support associated to the presence of the dendrimer, elastic and electrical characterization of $\mathrm{RC} / 4$ and $\mathrm{RC} / 4+$ dendrimer membranes in conditions related with membrane applications (aqueous solutions) were considered.

Measurements of membranes elastic response were performed with the samples submerged in a water bath to check the effect of the presence of the dendrimer and its maintenance in the hydrophilic cellulose support under such conditions (contact with aqueous solutions). Fig. 5 shows the normal stress-strain curves (F/S vs $\Delta L / L_{0}$ ) obtained for both membranes, where clear differences can be observed. This fact is rather interesting since it demonstrate the stability of this highly hydrophilic engineered membrane even in aqueous environments. Young modulus was obtained from the slope of the linear part of the curves, which corresponds at low elongations, and the following values were determined: $E(\mathrm{RC} /$ $4)=(24.5 \pm 1.8) \mathrm{MPa}$ and $\mathrm{E}(\mathrm{RC} / 4+$ dendrimer $)=(39 \pm 6) \mathrm{MPa}$. These results indicate that both hydrated samples can be considered as soft plastics $(E<70 \mathrm{MPa})$ and the presence of the dendrimer increases the Young modulus ( 20\%) and length at break ( 8\%).

Impedance spectroscopy measurements also permit us to get information on the presence of the dendrimer in the cellulosic structure and its effect on a characteristic physical parameter (electrical resistance) or a material specific parameter (conductivity) by analysing the impedance plots [39,41]. Variations of $Z_{\text {real }}$ values (related to electrical resistance/conductivity) with the applied frequency (Bode plot) are presented in Figs. 6 and 7. Particularly, Fig. 6 shows a comparison of the experimental values

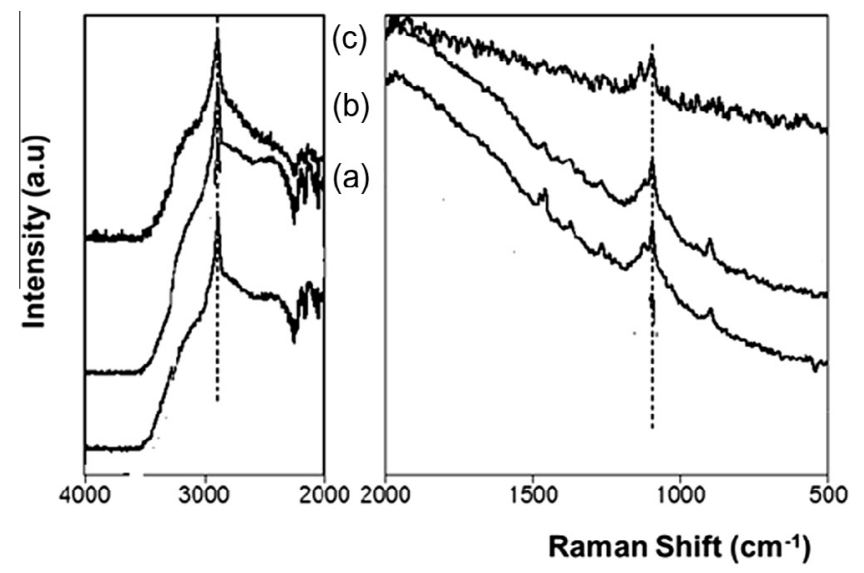

Fig. 4. $1064 \mathrm{~nm}$ FT-Raman spectra of membranes embedded of different electrolytes $10^{-3} \mathrm{M}$ aqueous solution: (a) the $\mathrm{RC} / 4$ membrane and $\mathrm{HgCl}_{2}$; (b) $\mathrm{RC} / 4+$ dendrimer membrane and $\mathrm{HgCl}_{2}$; (c) $\mathrm{RC} / 4+$ dendrimer membrane and $\mathrm{CdCl}_{2}$; (d) $\mathrm{RC} / 4+$ dendrimer membrane and $\mathrm{PbCl}_{2}$.

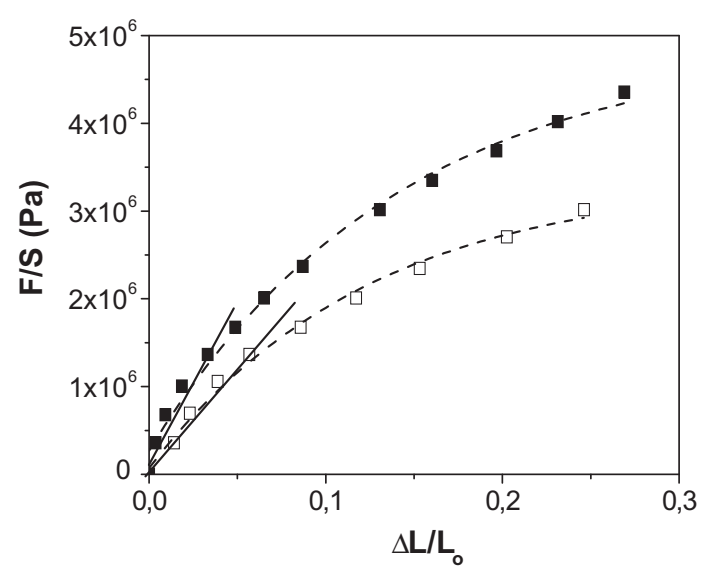

Fig. 5. Normal stress versus strain curves for hydrated membranes RC/4 ( $\square$ ) and RC/4+dendrimer ( $\mathbf{\square})$.

obtained for $\mathrm{RC} / 4$ and $\mathrm{RC} / 4+$ dendrimer membrane samples in hydrated state (after $24 \mathrm{~h}$ in distilled water), where slight differences in both interface and bulk membrane contribution can be observed, which is a confirmation of dendrimer inclusion into the cellulosic support structure already obtained from normal stressstrain curves but also of surface coverage; the increase in $Z_{\text {real }}$ values for the RC/4+dendrimer membrane is concordant with its more rigid structure due to the dendrimer inclusion but it also indicates the stability of the engineered membrane under adverse conditions (aqueous environment plus alternating electric field).

The effect of dendrimer on $Z_{\text {real }}$ values can clearly be observed in Fig. 7, where a comparison of the impedance values for the original and the dendrimer modified membranes, RC/4 and RC/4+dendrimer, after $24 \mathrm{~h}$ immersed in each electrolyte solution is shown. In this case, a reduction in $Z_{\text {real }}$ values for the $\mathrm{RC} / 4+$ dendrimer samples embedded with each one of the electrolytes studied is an indication of the higher number of charges and, consequently, the entrapment of heavy metal cations by the $\mathrm{RC} / 4+$ dendrimer membrane. Moreover, higher entrapment of $\mathrm{Hg}^{2+}$ cation (or stronger interaction) could be expected taking into account the slightly lower experimental values shown in Fig. 7c.

Diffusive electrolyte transport in a membrane caused by a concentration gradient $\left(\Delta c=c_{\mathrm{d}}-c_{\mathrm{r}}\right)$ is usually characterized by its permeability $\left(P_{\mathrm{s}}\right)$, which is the parameter indicating the total or partial restriction that the membrane offers to the transport of a

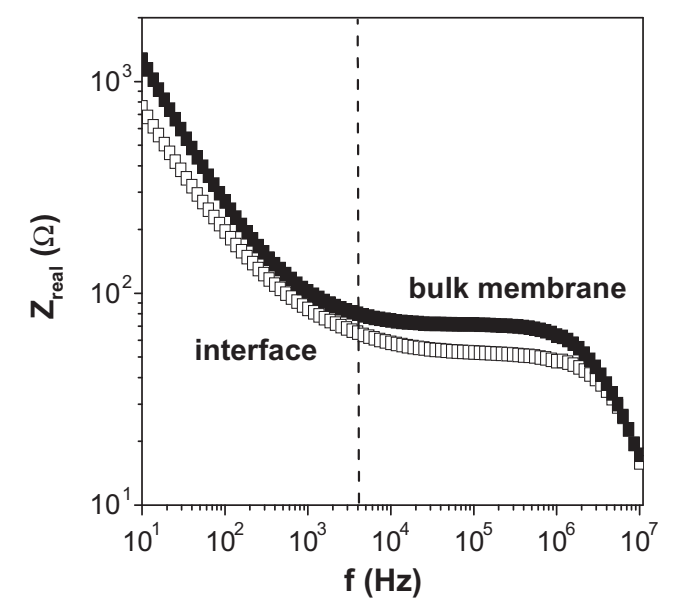

Fig. 6. Bode plots for $\mathrm{RC} / 4(\square)$ and $\mathrm{RC} / 4+$ dendrimer ( $\square$ ) membranes after $24 \mathrm{~h}$ immersion in distilled water. 

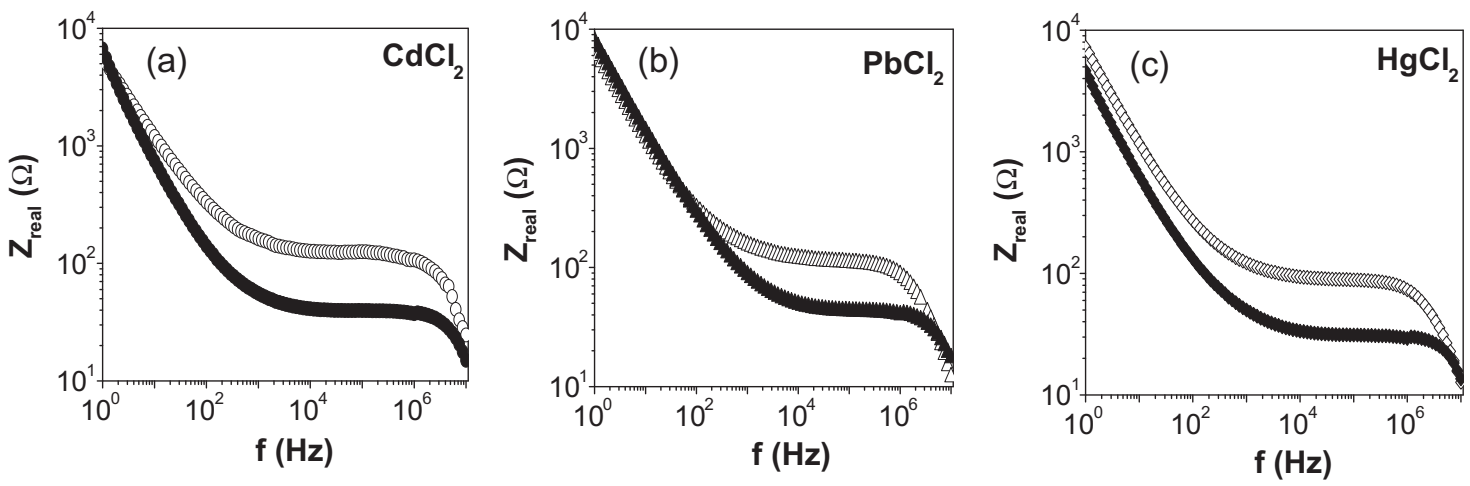

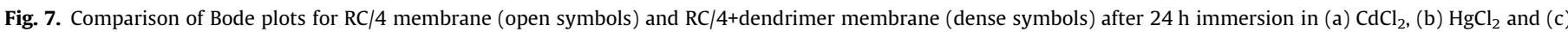
$\mathrm{PbCl}_{2}$.
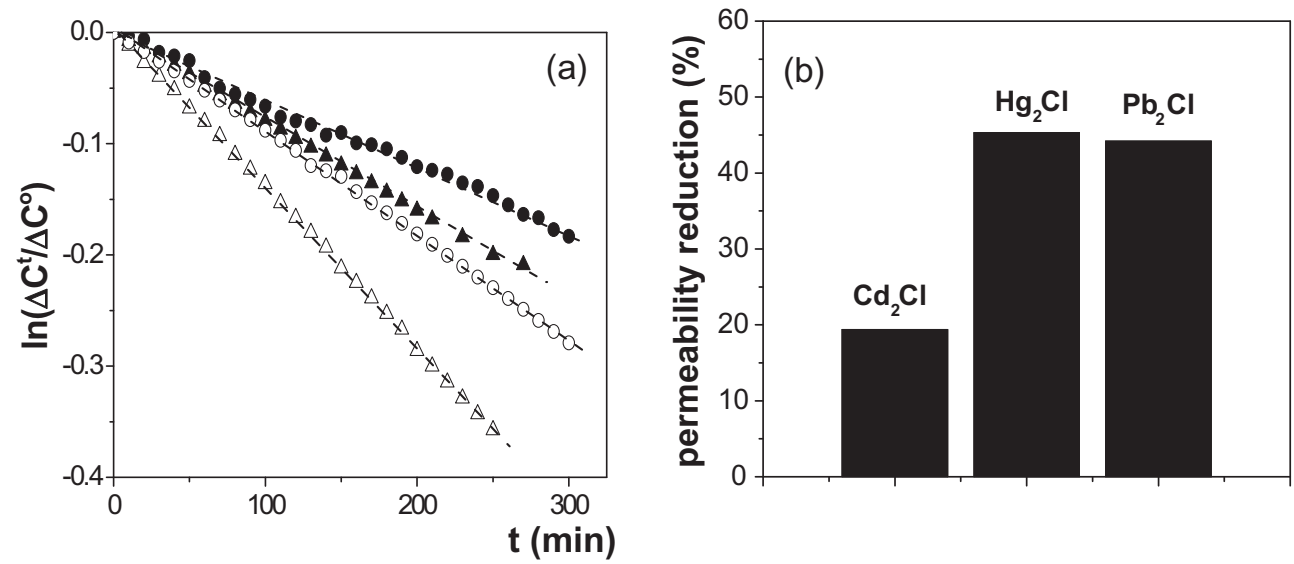

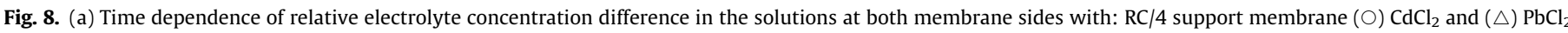

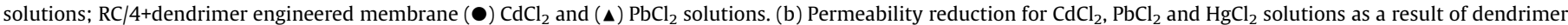
inclusion in the support membrane.

particular solute. In steady-state condition, the flux of mass per membrane area $\left(J_{s}\right)$ is related with the difference of concentrations between both membrane surfaces by Fick's first law [1]:

$J_{\mathrm{s}}=(\mathrm{d} n / \mathrm{d} t)(1 / S)=P_{\mathrm{s}}\left(c_{\mathrm{d}}-c_{\mathrm{r}}\right)=P_{\mathrm{s}} \Delta_{c}$

where $S$ indicates the membrane area. Since $\mathrm{d} n / \mathrm{d} t=\left(1 / V_{\mathrm{o}}\right)(\mathrm{d} c / \mathrm{d} t)$, Eq. (1) can be expressed as:

$\mathrm{d} c_{\mathrm{r}} /\left(c_{\mathrm{d}}-c_{\mathrm{r}}\right)=(S / V) P_{\mathrm{s}} \mathrm{d} t$

where $V$ is the volume of the solution, while $\mathrm{d} n$ and $\mathrm{d} t$ represent the mass crossing the membrane in an elemental period of time, respectively. Taking into account the mass continuity:

$c_{\mathrm{d}}^{0}+c_{\mathrm{r}}^{0}=c_{\mathrm{d}}^{t}+c_{\mathrm{r}}^{t}=$ cte

where $c_{\mathrm{d}}^{0}$ and $c_{\mathrm{r}}^{0}$ indicate the concentrations of initial donor and receiving solutions (time $t=0$ ), while $c_{\mathrm{d}}{ }^{t}$ and $c_{\mathrm{r}}{ }^{t}$ correspond to these concentrations at a certain time $t$; then, the following expression is obtained [7]:

$\ln \left(\left[\Delta c^{t} / \Delta c^{0}\right)\right]=-2(S / V) \cdot P_{\mathrm{s}} \cdot t$

Fig. 8a shows time evolution of the concentration ratio for each membrane and electrolyte studied where significantly lower values for the RC/4+dendrimer membrane with the same electrolyte can be observed, which indicates a reduction in the solute celerity through the engineered membrane. The effect of a membrane on solute transport can be quantified by determining its diffusive permeability, $P_{\mathrm{s}}$, which is determined from the slopes of the linear relationships according to Eq. (4). A decrease in diffusive permeability through the $\mathrm{RC} / 4+$ dendrimer membrane when compared with the RC/4 original sample was obtained for all the studied electrolytes, which is associated to the reduction in free volume among the cellulosic chains due to the presence of dendrimer. Permeability reduction $\left(\mathrm{PR}=\left(P_{\mathrm{s}}^{\mathrm{RC} / 4}-P_{\mathrm{s}}^{\mathrm{RC} / 4+\text { dendrimer }}\right) / P_{\mathrm{s}}^{\mathrm{RC} / 4}\right)$ for the different electrolytes is indicated in Fig. 8b. As can be observed, this effect is lower for the $\mathrm{CdCl}_{2}$ solution $(\sim 20 \%)$ than for $\mathrm{HgCl}_{2}$ and $\mathrm{PbCl}_{2}$ ones ( $\sim 45 \%)$, which could also open the possibility of heavy metal discrimination in case of electrochemical devices application.

\section{Conclusions}

In summary, innovative and simple thiol DAB-dendrimer incorporation in a highly hydrophilic cellulosic support by immersion in an aqueous solution has permitted us to obtain a nano-engineered system with potential application in heavy metal water remediation. As a result of DAB-dendrimer incorporation, elastic behaviour of the cellulosic support was improved by increasing Young modulus of wet samples ( 20\%) and a slight uptakes of heavy metals of environmental interest $(\mathrm{Cd}, \mathrm{Hg}$ and $\mathrm{Pb})$ according to the results supported by two different chemical and physical techniques (Raman and impedance spectroscopy analysis). Moreover, the reduction in diffusive permeability across the DAB-dendrimer engineered membrane obtained for different chloride salts $\left(\mathrm{CdCl}_{2}\right.$, $\mathrm{HgCl}_{2}$ and $\mathrm{PbCl}_{2}$ ) demonstrate its control on the transport of these contaminant metal ions when incorporate in remediation devices. 
Permeability reduction supports the possible application of dendrimer-engineered cellulosic membranes in electrochemical devices used in water remediation associated to heavy metal contamination.

\section{Acknowledgments}

The authors would like to thanks to Andalucía Tech Program (Universidad de Málaga, Spain) and the CICYT (MINECO, Spain, research project CTQ/2011-27770 FEDER funds) for partial financial support. Spanish Ministerio de Ciencia e Innovación (Project CTQ2009-12332-C02-01) is also acknowledged.

\section{References}

[1] M. Mulder, Basic Principles of Membrane Technology, Kluwer Academic Publishers, Dordrecht, 1992.

[2] R.W. Baker, Membrane Technology and Applications, John Wiley \& Sons, England, 2004.

[3] C. Fontàs, R. Tayeb, S. Tingry, M. Hidalgo, P. Seta, Transport of platinum(IV) through supported liquid membrane (SLM) and polymeric plasticized membrane (PPM), J. Membr. Sci. 263 (2005) 96-102.

[4] C. Gherasim, G. Bourceany, R. Olariu, C. Aresene, A novel polymer inclusion membrane applied in chromium(VI) separation from aqueous solutions, J. Hazard. Mater. 197 (2011) 244-253.

[5] R. Güell, E. Anticó, S.D. Kolev, J. Benavente, V. Salvadó, C. Fontàs, Development and characterization of polymer inclusion membranes for the separation and speciation of inorganic As species, J. Membr. Sci. 383 (2011) 88-95.

[6] M. Hofman, R. Pietrzak, Copper ions removal from liquid phase by Polyethersulfone (PES) membranes functionalized by introduction of carbonaceous materials, Chem. Eng. J. 215-216 (2013) 216-221.

[7] D.L. Gilbert, T. Okano, T. Miyata, S.W. Kim, Molecular diffusion through collagen membranes, Int. J. Pharm. 47 (1988) 79-85

[8] J.D. Ramos, C. Milano, V. Romero, S. Escalera, M.C. Alba, M.I. Vázquez, J. Benavente, Water effect on physical-chemical and elastic parameters for a dense cellulose regenerated membrane. Transport of different aqueous electrolyte solutions, J. Membr. Sci. 352 (2010) 153-159.

[9] M.I. Vázquez, V. Romero, J. Hierrezuelo, R. Rico, J.M. López-Romero, M.R. LópezRamírez, J. Benavente, Effect of lipid nanoparticles inclusion on transport parameters through regenerated cellulose membranes, J. Membr. Sci. 370 (2011) 70-75.

[10] M. Algarra, B.B. Campos, B. Alonso, C.M. Casado, J.C.G. Esteves da Silva, J. Benavente, Inclusion of thiol DAB dendrimer/CdSe quantum dots based in a membrane structure: surface and bulk membrane modification, Electrochim. Acta 89 (2013) 652-659.

[11] D.A. Tomalia, A.N. Naylor, W.A. Goddard III, Starburst dendrimers: molecular level control of size, shape, surface, chemistry and topology, Angew. Chem. Int. Ed. Engl. 29 (1990) 138-175.

[12] J.M.J. Fréchet, Functional polymers and dendrimers: reactivity, molecular architecture, and interfacial energy, Science 263 (1994) 1710-1715.

[13] J.M.J. Fréchet, D.A. Tomalia, Dendrimers and Other Dendritic Polymers, WileyVCH, Weinheim, 2001.

[14] Y. Cheng, Dendrimer Based in Drug Delivery Systems, John Wiley \& Sons, Hoboken, NJ, 2012.

[15] C.N. Moorefield, S. Perera, G.R Newkome, Dendrimer chemistry: supramolecular perspectives and applications, in: Y. Cheng (Ed.), Dendrimerbased Drug Delivery Systems: From Theory to Practice, John Wiley \& Sons Hoboken, NJ, 2012 (Chapter 1).

[16] U. Boas, P.M. Heegaard, Dendrimers in drug research, Chem. Soc. Rev. 33 (2004) 43-63.

[17] M. Algarra, B.B. Campos, M.S. Miranda, J.C.G. Esteves da Silva, CdSe quantum dots capped PAMAM dendrimer nanocomposites for sensing nitroaromatic compounds, Talanta 83 (2011) 1335-1340.

[18] J.C.G. Esteves da Silva, M. Algarra, B.B. Campos, Synthesis and analytical applications of Quantum Dots coated with different generations of DAB dendrimers, in: B. Reddy (Ed.), Advances in Nanocomposites-Synthesis, Characterization and Industrial Applications, IN-TECH, 2011, pp. 23-38.
[19] M. Algarra, B.B. Campos, B. Alonso, M.S. Miranda, A.M. Martínez, C.M. Casado, J.C.G. Esteves da Silva, Thiolated DAB dendrimers and CdSe quantum dots nanocomposites for Cd(II) or Pb(II) sensing, Talanta 88 (2012) 403-407.

[20] G. Jie, J. Yuan, Quantum dots-based multifunctional dendritic superstructure for amplified electrochemiluminescence detection of ATP, Biosens. Bioelectron. 31 (2012) 69-76.

[21] J.M. Oliveira, A.J. Salgado, N. Sousa, J.F. Mano, R.L. Reisa, Dendrimers and derivatives as a potential therapeutic tool in regenerative medicine strategies - a review, Prog. Polym. Sci. 35 (2010) 1163-1194.

[22] F. Vogtle, G. Richardt, N. Werner, Dendrimer Chemistry: Concepts, Syntheses, Properties, Applications, Wiley-VCH, Weinheim, 2009.

[23] A. Rether, M. Schuster, Selective separation and recovery of heavy metal ions using water-soluble N-benzoylthiourea modified PAMAM polymers, React. Funct. Polym. 57 (2003) 13-21.

[24] M.S. Diallo, S. Christie, P. Swaminathan, L. Balogh, X. Shi, W. Um, C. Papelis, W.A. Goddard 3rd, J.H. Johnson Jr., Dendritic chelating agents. 1. Cu(II) binding to ethylene diamine core poly(amidoamine) dendrimers in aqueous solutions, Langmuir 20 (2004) 2640-2651.

[25] M.S. Diallo, S. Christie, P. Swaminathan, J.H. Johnson Jr., W. Goddard, Dendrimer enhanced ultrafiltration. 1. Recovery of $\mathrm{Cu}(\mathrm{II})$ from aqueous solutions using PAMAM dendrimers with ethylene diamine core and terminal $\mathrm{NH}_{2}$ groups, Environ. Sci. Technol. 39 (2005) 1366-1377.

[26] M.S. Diallo, W. Arasho, J.H. Johnson Jr., W.A. Goddard, Dendritic chelating agents. 2. U(VI) binding to poly(amidoamine) and poly(propyleneimine) dendrimers in aqueous solutions, Environ. Sci. Technol. 42 (2008) 1572-1579.

[27] Y. Xu, D. Zhao, Removal of $\mathrm{Cu}(\mathrm{II})$ from contaminated soil using pamam dendrimers, Environ. Sci. Technol. 39 (2005) 2369-2375.

[28] M.A. Barakat, M.H. Ramadan, M.A. Alghamadi, S.S. Algarny, H.L. Woodcock, J. Kuhn, Remediation of $\mathrm{Cu}(\mathrm{II}), \mathrm{Ni}(\mathrm{II})$, and $\mathrm{Cr}(\mathrm{III})$ ions from simulated wastewater by dendrimer/titania composites, J. Environ. Manage. 117 (2013) 50-57.

[29] S. Duan, T. Kouketsu, S. Kazama, K.J. Yamada, Development of PAMAM dendrimer composite membranes for $\mathrm{CO}_{2}$ separation, J. Membr. Sci. 283 (2006) 2-6.

[30] T. Kouketsu, S. Duan, T. Kai, S. Kazama, K. Yamada, PAMAM dendrimer composite membrane for $\mathrm{CO}_{2}$ separation: formation of a chitosan gutter layer, J. Membr. Sci. 287 (2007) 51-59.

[31] S. Tomita, K. Sato, J. Anzai, Layer-by-layer assembled thin films composed of carboxyl-terminated poly(amidoamine) dendrimer as a pH-sensitive nanodevice, J. Colloid Interface Sci. 326 (2008) 35-40.

[32] S. Duan, F.A. Chowdhury, T. Kai, S. Kazama, Y. Fujioka, PAMAM dendrimer composite membrane for $\mathrm{CO}_{2}$ separation: addition of hyaluronic acid in gutter layer and application of novel hydroxyl PAMAM dendrimer, Desalinisation 234 (2008) 278-285.

[33] A. Sarkar, P.I. Carver, T. Zhang, A. Merrington, K.J. Bruza, J.L. Rousseau, S.E. Keinath, P.R.J. Dvornic, Dendrimer-based coatings for surface modification of polyamide reverse osmosis membranes, J. Membr. Sci. 349 (2010) 421 428.

[34] Q. Zhang, N. Wang, L. Zhao, T. Xu, Y. Cheng, Polyamidoamine dendronized hollow fiber membranes in the recovery of heavy metal ions, ACS Appl. Mater. Interfaces 349 (2013) 1907-1912.

[35] D. Hiraiwa, T. Yoshimura, K. Esumi, Interaction forces between poly(amidoamine) (PAMAM) dendrimers adsorbed on gold surfaces, J. Colloid Interface Sci. 298 (2006) 982-986.

[36] Y. Gao, A.M. Sáez de Jubera, B.J. Mariñas, Nanofiltration membranes with modified active layer using aromatic polyamide dendrimers, Adv. Funct. Mater. 23 (2013) 598-607.

[37] V. Katzur, M. Eichler, E. Deigele, C. Stage, P. Karageorgiev, J. Geis-Gerstorfer, G. Schmalz, S. Ruhl, F. Rupp, R. Müller, Surface-immobilized PAMAM-dendrimers modified with cationic or anionic terminal functions: physicochemical surface properties and conformational changes after application of liquid interface stress, J. Colloid Interface Sci. 366 (2012) 179-190.

[38] S. Connolly, S.N. Rao, D. Fitzmaurice, Characterization of protein aggregated gold nanocrystals, J. Phys. Chem. B 104 (2000) 4765-4776.

[39] J. Benavente, Use of impedance spectroscopy for characterization of membranes and the effect of different modifications, in: N. Hilal, M. Khayet, Ch.J. Wright (Eds.), Membrane Modification: Technology and Applications, CRC Press, 2012.

[40] L. Pelaez, M.I. Vázquez, J. Benavente, Interfacial and fouling effects on diffusional permeability across a composite ceramic membrane, Ceram. Int. 36 (2010) 797-801.

[41] R.J. MacDonals, Impedance Spectroscopy, Wiley, New York, 1987. 